\title{
PREDICTORS OF RESPONSE TO PLASMAPHERESIS IN AUTOIMMUNE NEUROPATHIES
}

\author{
By \\ Yasser El-Sayed Mukhtar, Tarek Ibrahim Mnecie, Hassan Kawashti \\ Gad and Mohammed Ahmed Zaki \\ Neurology Department, Faculty of Medicine, Al-Azhar University, Cairo, Egypt \\ *Corresponding Author: Mukhtar, Yasser El-Sayed, \\ E-mail: yassermukhtar1@gmail.com
}

\begin{abstract}
Background: Immune-mediated neuropathies represent a significant portion of cases encountered by neurologists. The scope of responsive neuropathies, the extent of response to plasmapheresis and its predictors varies widely.

Objective: To recognize predictors of response to plasmapheresis in autoimmune-neuropathies.

Patients and Methods: Seventy-six subjects; 61 Guillain-Barre syndrome (GBS) patients and 15 chronic inflammatory demyelinating polyneuropathy (CIDP) patients were recruited and evaluated using Medical Research Council sum score (MRCSS) and Modified Neuropathy Disability Score (NDS); on admission, 2 weeks and 3 months after six session of plasmapheresis. Different clinical, laboratory and neurophysiological variables were evaluated as possible predictors of response.

Results: Of 61GBS patients, after 3 months, $41 \%(\mathrm{n}=25)$ of them were poor-responders to plasmapheresis ( $<50 \%$ increase in MRCSS), and 59\% ( $\mathrm{n}=36)$ were good-responders. Older age, higher MRCSS on admission, lower NDS on admission, cyto-albuminous dissociation, electro-physiological evidence of axonal nerve affection and low NLR were predictors for poor response to plasmapheresis in GBS patients. Of 15 CIDP patients, after 3 months, $53.3 \%(\mathrm{n}=8)$ of them were poor-responders to plasmapheresis $(<30 \%$ increase in MRCSS), and 46.7\% ( $n=7)$ were good-responders. Higher MRCSS on admission, low CMAP amplitude, low MCV and long time between onset of the health problem and start of plasmapheresis were predictors for poor response to plasmapheresis in CIDP patients.
\end{abstract}

Conclusion: Response to plasmapheresis in autoimmune neuropathies is variables and depends on several factors that can predict it.

Keywords: Guillain-Barré, Demyelinating Polyneuropathy, Prognosis, Plasmapheresis.

\section{INTRODUCTION}

Autoimmune neuropathies are an etiologically heterogeneous entity with variable clinical presentations. The common autoimmune neuropathies include; Guillain-Barré Syndrome (GBS), Chronic Inflammatory Demyelinating Polyneuropathy (CIDP), Multifocal Motor
Neuropathy with conduction block and Polyneuropathies associated with $\operatorname{IgM}$ monoclonal gammopathies (Shimizu et al., 2019).

GBS is a collection of clinical syndromes that presents as an acute inflammatory polyradiculoneuropathy; distinguished by an acute onset, rapid 
progression, symmetric muscle weakness, unstable walking, and hypo- or areflexia. Some types of it may affect exclusively the cranial nerves or had pure motor involvement and axonal injury (Willison et al., 2016).

Based on several studies generating class I evidence, plasmapheresis has been established as effective treatment in GBS therapy (type A recommendation) (Hugh et al., 2016).

CIDP is the commonest chronic immune-mediated inflammatory polyneuropathy, and includes many subtypes that belong to the spectrum of causally treatable neuropathies (Lehmann et al., 2019).

The term (CIDP) has been used to distinguish patients with a chronically progressive or relapsing symmetric sensorimotor manifestations with cytoalbuminous dissociation and interstitial and perivascular endoneuronal infiltration by lymphocytes and macrophages (Jeffrey et al., 2020).

There is class I evidence that plasmapheresis is superior to sham treatment in CIDP, so, recommended in the treatment of CIDP (type A recommendation) (Dyck and Tracy, 2018).

Most of Multifocal motor neuropathy patients didn't benefit from plasmapheresis in different studies, and some reported severe clinical worsening (class IV evidence, type U recommendation) (Shimizu et al., 2019).

\footnotetext{
Response to treatment with plasmapheresis in autoimmune neuropathies is variable. We believe that predicting that response and identifying possible predictors is vital, particularly if
}

different choices are available. This gains a greater importance in low resource circumstances particularly that plasmapheresis is a costly procedure and is not without complications.

The aim of this study was to recognize predictors of response to plasmapheresis in two entities of autoimmune-neuropathies; GBS and CIDP.

\section{PATIENTS AND METHODS}

This study has been designed as analytical prospective observational study, and was conducted at Al-Azhar University Hospitals and Neurology Department, Nasser Institute Hospital within the period between November 2015 and Jan 2020.

The study included patients were diagnosed with GBS according to the diagnostic criteria of Van Doorn (2013) and van den Berg et al. (2014). Patients were diagnosed with CIDP, using the European Federation of Neurological Societies/Peripheral Nerve Society Diagnostic Criteria (EFNS/PNS), from all ages of both genders. Convenient sample of seventy-six (76) patients have been recruited.

The requirements of Al-Azhar University Ethics Committee were fulfilled, and an informed written consent had been obtained from every patient before participating in the study.

At time of admission, all cases were subjected to: medical research council sum score (MRCSS) for muscle strength, and modified neuropathy disability score (NDS) for sensory functions, nerve conduction studies, routine laboratory 
work up, and other laboratory/imaging investigations whenever needed.

Plasmapheresis was applied for patients: one session every other day over two weeks (6 sessions as a standard). Plasmapheresis was accomplished through centrifuge-based platforms; "CobeSpectra" and "Fresenius COM.TEC" device series, with appropriate patient preparation, monitoring, symptomatic adjustments and exchange technique. Two weeks after starting plasmapheresis, all cases were subjected to MRCSS and NDS. That was repeated after three months.

Each of The GBS patients group and CIDP patient group was divided into two groups: Group A: Good-responders to treatment $(\geq 50 \%[30 \%$ in CIDP], increase in MRCSS, and/or decrease in NDS), and Group B: Poor-responders to treatment $(<$ $50 \%$ [30\% in CIDP] increase in MRCSS and/or decrease in NDS).

For each scale, we compared and analyzed the two groups as regard demographic, clinical, biochemical and neurophysiological characteristics to recognize predictors of response.

\section{Statistical analysis:}

Analytical statistics for the association between different variables and the outcome variables were done using independent $\mathrm{T}$ test for normally distributed numerical variables (mean and standard deviation) and the nonparametric test Mann Whitney U test for the non-normally distributed numerical variables (median and interquartile range). The association between categorical variables (frequency and relative frequency) and different outcome variables was done using Chi square test and Fisher's exact test. Binary logistic regression was used to study the association between predictive variables and the outcome variable in GBS patients. $\mathrm{P}$-value less than $(0.05)$ were considered significant.

\section{RESULTS}

Sixty-one GBS patients; $63.9 \%(n=39)$ of them were males and $36.1 \% \quad(n=22)$ were females. The age distribution ranged from 5 to 80 years; the mean $\pm \mathrm{SD}$ was $40.5 \pm 17.2$ years. $44.3 \%(n=27)$ of GBS patients had history of antecedent infection, $31.1 \%(\mathrm{n}=19)$ had cranial nerve affection, and $77 \%(n=47)$ had Cytoalbuminous Dissociation. Only 4.9\% ( $\mathrm{n}=$ 3 ) of them needed artificial ventilation. Also, $1.6 \% \quad(n=1)$ had autonomic symptoms. The neutrophil-lymphocyte ratio (NLR) ranged from 1.1 to 3.7 , mean value $\pm \mathrm{SD}$ was $2.4 \pm 1$. The ESR ranged from 5 to 45 , mean value \pm SD was 23.7 \pm 9.6 . And CRP ranged from 2 to 52 , mean value \pm SD was $5.5 \pm 6.3$. MRCSS on admission ranged from 2 to 48, mean value \pm SD was $27.1 \pm 15.9$. By electrodiagnosis, $39.3 \% \quad(n=24)$ had evident demyelination and $39.3 \% \quad(n=24)$ had axonal changes. The remaining percent had mixed pattern of affection (Table 1). 
Table (1): MRCSS in GBS

\begin{tabular}{|c|c|c|c|c|c|c|}
\hline \multirow{3}{*}{ Parameters } & \multicolumn{5}{|c|}{$\begin{array}{l}\text { According to percent of increase in } \\
\end{array}$} & \multirow[b]{3}{*}{ P-value } \\
\hline & \multicolumn{2}{|c|}{\begin{tabular}{|c|} 
Median at $2 \mathrm{w}$ \\
Poor-responders Good-responders
\end{tabular}} & \multirow{2}{*}{$\begin{array}{c}\text { P- } \\
\text { value }\end{array}$} & \multicolumn{2}{|c|}{ Median at $3 \mathbf{~ m}$} & \\
\hline & $\begin{array}{c}\text { Poor-responder } \\
\text { 42.6\% }(\mathrm{n}=26)\end{array}$ & $\begin{array}{c}\text { Good-responders } \\
\mathbf{5 7 . 4 \%}(\mathrm{n}=\mathbf{3 5})\end{array}$ & & $\begin{array}{c}\text { Poor-responders } \\
41 \%(n=25)\end{array}$ & $\begin{array}{c}\text { Good-responders } \\
59 \%(\mathrm{n}=36)\end{array}$ & \\
\hline $\begin{array}{c}\text { NDS on } \\
\text { admission }\end{array}$ & 6.00 & 8.00 & 0.015 & 6.00 & 7.00 & 0.015 \\
\hline $\begin{array}{l}\text { MRCSS on } \\
\text { admission }\end{array}$ & 48.00 & 12.00 & $<0.001$ & 48.00 & 12.00 & $<0.001$ \\
\hline $\begin{array}{l}\text { NLR on } \\
\text { admission }\end{array}$ & 3.01 & 1.88 & 0.246 & 3.28 & 1.88 & 0.232 \\
\hline
\end{tabular}

According to percent of decrease in NDS, GBS patients were devided into good and poor responders and analysed different variants assumed to be possible predictors of response to plasmapheresis (Table 2).

Table (2): NDS at 2 weeks in GBS

\begin{tabular}{|c|c|c|c|c|}
\hline \multicolumn{2}{|c|}{ NDS at 2 weeks (GBS) } & $\begin{array}{l}\text { Poor-responders } \\
\text { 86.9\% }(n=53)\end{array}$ & $\begin{array}{c}\text { Good-responders } \\
13.1 \%(n=8)\end{array}$ & P-value \\
\hline \multicolumn{2}{|c|}{ Age (years) (Median) } & 45.00 & 29.50 & 0.035 \\
\hline \multicolumn{2}{|c|}{ NDS on admission (Median) } & 6.00 & 8.00 & $<0.001$ \\
\hline \multicolumn{2}{|c|}{ MRCSS on admission (Median) } & 24.00 & 12.00 & 0.002 \\
\hline \multicolumn{2}{|c|}{ NLR on admission (Median) } & 1.96 & 3.42 & 0.005 \\
\hline \multirow{3}{*}{$\begin{array}{c}\text { NCS on admission } \\
\mathrm{N}(\%)\end{array}$} & Demyelinating & $17(32.1 \%)$ & $7(87.5 \%)$ & \multirow{3}{*}{0.012} \\
\hline & Axonal & $24(45.3 \%)$ & $0(0.0 \%)$ & \\
\hline & Mixed & $12(22.6 \%)$ & $1(12.5 \%)$ & \\
\hline \multirow{2}{*}{ Cyto-alb. Dissociation } & Absent & $917.0 \%$ & $562.5 \%$ & \multirow{2}{*}{0.012} \\
\hline & Present & $44(83.0 \%)$ & $3(37.5 \%)$ & \\
\hline
\end{tabular}

We found that the variables showed statistically significant difference between the two groups were the median age was significantly higher in poor-responders group (NDS at 2w), The NDS on admission was lower in poor responders (NDS at $2 \mathrm{w}-\mathrm{MRCSS}$ at $2 \mathrm{w}, 3 \mathrm{~m}$ ), The MRCSS on admission was higher in poorresponders (NDS at $2 \mathrm{w}-\mathrm{MRCSS}$ at $2 \mathrm{w}$, $3 \mathrm{~m}$ ), more patients of the non-responders group had Cyto-albuminous Dissociation (NDS at $2 \mathrm{w}$ ), Increase in percent of patients who had electro-diagnostic evidence of predominantly axonal pattern of neuropathy within the poor-responder group (NDS at $2 \mathrm{w}$ ) and the Neutrophil Lymphocyte Ratio (NLR) values were significantly lower in poor-responders group (NDS at $2 \mathrm{w}$ ).
A logistic regression analysis was done to examine the association between different variables and the occurrence of more than $50 \%$ improvement in the MRCSS score. Significant variables in the bivariate analysis were included in the model. After controlling for other variables, the only significant predictor of more than $50 \%$ improvement in the MRCSS score are MRCSS on admission $(\mathrm{OR}=0.92)$. The higher the MRCSS at admission the lower the probability of occurrence of more than $50 \%$ improvement in the MRCSS score.

Our study did not notice any statistically significant distinction between poor-responder and good responder groups as regard time to start treatment, the need for ventilator at nadir, history of preceding infection, gender difference, 
cranial nerve affection and the presence of autonomic symptoms.

We recruited fifteen CIDP patients; 63 percent $60 \%(n=9)$ of them were females and $40 \%(n=6)$ of them were males. The distribution of the ages of group was ranging from 20 to 71 years old; the mean age \pm SD was $47.4 \pm 14.07$ years.

In the CIDP patient group; the MRCSS on admission ranged from 14 to 48 with mean \pm SD was $32.93 \pm 10.33$. And NDS values ranged from 2 to 10 with mean \pm SD was $5.73 \pm 1.98$. We also found $40 \%$ $(\mathrm{n}=6)$ of them had Cyto-albuminous Dissociation.

The time period between onset of symptoms and starting treatment ranged from 2 to 60 months with the mean value \pm SD was $16.67 \pm 18.2$. Moreover, $20 \%$ $(n=3)$ of patients received other Immunosuppressive therapy before starting plasmapheresis with poor response and $60 \% \quad(n=9)$ of patients received steroid treatment, from them $77.78 \%(\mathrm{n}=7)$ responded poorly to steroid therapy.

According to percent of increase in MRCSS and percent of decrease in NDS, we divided GBS patients into good and poor responders and analysed different variants assumed to be possible predictors of response to plasmapheresis (Table 3).

Table (3): MRCSS and NDS in CIDP

\begin{tabular}{|c|c|c|c|c|c|c|}
\hline \multirow[b]{2}{*}{ Parameters } & \multicolumn{2}{|c|}{ Median at $2 \mathrm{w}$} & \multirow[b]{2}{*}{$\begin{array}{c}\text { P- } \\
\text { value }\end{array}$} & \multicolumn{2}{|c|}{ Median at $3 \mathrm{~m}$} & \multirow[b]{2}{*}{ P-value } \\
\hline & $\begin{array}{c}\text { Poor- } \\
\text { responders } \\
\mathbf{6 6 . 7 \%} \\
(\mathbf{n}=\mathbf{1 0}) \\
\end{array}$ & $\begin{array}{c}\text { Good- } \\
\text { responders } \\
\mathbf{3 3 . 3 \%} \\
(\mathbf{n}=\mathbf{5}) \\
\end{array}$ & & $\begin{array}{c}\text { Poor- } \\
\text { responders } \\
\mathbf{5 3 . 3 \%} \\
(\mathbf{n}=\mathbf{8}) \\
\end{array}$ & $\begin{array}{c}\text { Good- } \\
\text { responders } \\
\mathbf{4 6 . 7 \%} \\
(\mathbf{n}=7) \\
\end{array}$ & \\
\hline MRCSS on admission & 41 & 28 & 0.04 & 42 & 28 & 0.002 \\
\hline CMAP amplitude Ulnar & 1 & 3.6 & 0.078 & 0.9 & 2.2 & 0.04 \\
\hline MCV Ulnar & 33 & 50 & 0.026 & 28.4 & 50 & 0.075 \\
\hline $\begin{array}{c}\text { time from Onset of } \\
\text { symptoms to start of PE } \\
\text { (in months) }\end{array}$ & 15 & 3 & 0.04 & 31 & 2 & 0.013 \\
\hline
\end{tabular}

We found that the variables showed statistically significant difference between the two groups were the patient score on MRCSS was significantly higher among the poor-responder group (MRCSS at $2 \mathrm{w}$ \& 3m), CMAP amplitude for ulnar nerve were significantly lower among the poorresponder group (NDS at $3 \mathrm{~m}$ ), MCV for ulnar nerve were significantly lower among the non-responder group(NDS at $3 \mathrm{~m})$ and the time from onset of symptoms till start of plasmapheresis were significantly higher among the poorresponders (NDS at $2 \mathrm{w} \& 3 \mathrm{~m}$ ).

In our study, we could not find any statistically significant difference between the good-responder group and the poorresponder group of CIDP patients as regard; NDS on admission, NLR on admission, Sex, presence of muscle atrophy on admission, Cyto-albuminous Dissociation, Steroid Exposure and Immunosuppressive Drug Exposure. 


\section{DISCUSSION}

In our study, older age was predictor for poor response to PP in GBS patients. This prophetic ability has been confirmed through the study of Willison (2016).

In our study, higher MRCSS and lower NDS on admission were predictor for poor response $(<50 \%$ change in clinical score) to $\mathrm{PP}$ in GBS patients. Our results confirmed that the poorer the clinical score, the more benefit can the patient get from plasmapheresis, and patients who had better scores on clinical scores will not get much benefit from this procedure. This was consistent with Verboon (2017) who doubted treatment efficacy in patients. This was consistent with Hughes et al. (2014) and Chevret et al. (2017).

In our study, cyto-albuminous dissociation was predictor for poor response to plasmapheresis in GBS patients. Zhang et al. (2018) reported the contrary. However, in our study this significance was evident solely on NDS at period of 2 weeks and was not present on the same scale after three months.

In our study, electrophysiological proof of nerve axonal affection was predictor for poor response to PP in GBS patients. This ability has been confirmed in a similar study by Zhang et al. (2018).

In our study, low NLR was predictor for poor response to PP in GBS patients. This ability has been confirmed in similar studies; Sahin et al. (2017) and Hashim et al. (2020).

Our study did not notice any statistically significant distinction between groups as regard time to begin treatment. That was against the finding of Chevret et al. (2017) and Prasad et al. (2017). This may be explained as $86.9 \%$ of our GBS patient group started treatment early within one week.

Our study did not notice any statistically significant distinction between groups as regard the need for ventilator, preceding infection and autonomic symptoms. That was against the finding of Zhang et al. (2018). This difference is probably due to logistic factors in our study, as there was limitation in admitting critically ill patients due to shortage in ICU beds, so the percent of patients who needed ventilators or had dysautonomic findings was small in our study. Also, only $4.9 \%$ of our patients needed ventilation, and only $1.6 \%$ had autonomic symptoms. Non-specified type of infection in our study may justify our results as preceding upper respiratory infection is related to better prognosis, while GIT infection is related to poor prognosis (Kuwabara, 2011).

Our results showed insignificant difference between groups as regard gender, cranial nerve affection which was similar to the results of Prasad et al. (2017).

In our study, higher MRCSS was predictor for poor response to plasmapheresis in CIDP patients. That was not the case in the study introduced by Lehmann (2019) who reported that MRC scale was not significantly different between the patients with remission and the others.

Wu et al. (2015) reported disability at the time of diagnosis was the strongest predictor of poor outcome. However, our study confirms the predictor value for percent of improvement in response to 
plasmapheresis not long term general outcome.

In our study, lower CMAP and MCV amplitude was predictor for poor response to PP in CIDP patients. This predictive ability has been confirmed in the stud of Rajabally et al. (2011).

In our study, longer disease duration before plasmapheresis was predictor for poor response to plasmapheresis in CIDP patients. This predictive ability has been reported by Lehmann (2019).

In our study, we could not notice any statistically significant distinction between the good-responder group and the poorresponder group of CIDP patients as regard; Age, NDS on admission, NLR on admission, Sex, presence of muscle atrophy on admission, Cyto-albuminous Dissociation, Steroid Exposure and Immunosuppressive Drug Exposure. This was consistent with report of Lehmann (2019).

Regression analysis couldn't be performed for the CIDP patient group in our study as the sample size was unsuitable for satisfying the assumption required for regression analysis.

\section{CONCLUSION}

Autoimmune neuropathies (GBS \& CIDP) are responsive to plasmapheresis in variable degrees. Older age, higher MRCSS on admission, lower NDS on admission, cyto-albuminous dissociation, electrophysiological evidence of axonal affection and low NLR were predictors for poor response to plasmapheresis in GBS patients. Higher MRCSS on admission, low CMAP amplitude, low MCV and long time between onset of symptoms and begin of plasmapheresis were predictor for poor response to plasmapheresis in CIDP patients.

\section{REFERENCES}

1. Chevret S, Hughes RAC and Annane D (2017): Plasma exchange for Guillain-Barré syndrome. Cochrane Database of Systematic Reviews, Issue 2. Art. No.: CD001798.

2. Dyck PJB and Tracy JA (2018): History, Diagnosis, and Management of Chronic Inflammatory Demyelinating Polyradiculoneuropathy. Mayo Clin Proc, 93:777- 785 .

3. Hashim NA, Samir WM and Mohammed EE (2020): Neutrophil-lymphocyte ratio and response to plasmapheresis in Guillain-Barré syndrome: a prospective observational study. The Egyptian Journal of Neurology, Psychiatry and Neurosurgery, 56:17-38.

4. Hugh J Willison, Bart C Jacobs, Pieter A and Van Doorn (2016): Guillain-Barré syndrome. Lancet; 388: 717-727.

5. Hughes RA, Swan AV and van Doorn PA (2014): Intravenous immunoglobulin for Guillain- Barré syndrome. Cochrane Database Syst. Rev, 9: CD002063.

6. Jeffrey A. A (2020): The Misdiagnosis of CIDP: A Review. Neurol Ther, 9:43-54.

7. Kuwabara S (2011): Does Campylobacter jejuni infection elicit axonal or demyelinating Guillain-Barre syndrome, or both? J Neurol Neurosurg Psychiatry. 82(3):238-312.

8. Lehmann HC, Burke D and Kuwabara $S$ (2019): Chronic inflammatory demyelinating polyneuropathy: update on diagnosis, immunopathogenesis and treatment $\mathrm{J}$ Neurol Neurosurg Psychiatry, 90:981-987.

9. Lehmann HC, Burke D and Kuwabara S (2019): Chronic inflammatory demyelinating polyneuropathy: update on diagnosis, immunopathogenesis and treatment $\mathrm{J}$ Neurol Neurosurg Psychiatry, 90:981-987.

10. Prasad HB, Borse RT, Avate AN and Neelesh P (2017): Prognostic Indicators of Response to Plasmapheresis in Patients of Guillain Barre Syndrome. Journal of the 
Association of Physicians of India, 65: 119167.

11. Rajabally $Y$ and Narasimhan $M$ (2011): Distribution, clinical correlates and significance of axonal loss and demyelination in chronic inflammatory demyelinating polyneuropathy. Eur J Neurol; 18:293-299.

12. Sahin S, Cinar N and Karsidag S (2017): Are cerebrospinal fluid protein levels and plasma neutrophil/ lymphocyte ratio associated with prognosis of Guillain- Barré syndrome. Neurol Int., 9:7032-6.

13. Shimizu F, Oishi M, Sawai S, Beppu M, Misawa S, Matsui N, Miyashiro A, Maeda T, Takeshita Y, Nishihara H, Sano Y, Sato R, Kaji R, Kuwabara $S$ and Kanda T (2019): Increased IP-10 production by blood-nerve barrier in multifocal acquired demyelinating sensory and motor neuropathy and multifocal motor neuropathy. J Neurol Neurosurg Psychiatry, 90(4):444-450.

14. Van den Berg B, Walgaard C, Drenthen J, Fokke C, Jacobs BC and van Doorn PA (2014): Guillain-Barre syndrome: pathogenesis, diagnosis, treatment and prognosis. Nat Rev Neurol; 10: 469-82.
15. Van Doorn PA (2013): Diagnosis, treatment and prognosis of Guillain-Barre syndrome (GBS), 42: e193-201.

16. Verboon C, van Doorn PA and Jacobs BC (2017): Treatment dilemmas in Guillain- Barré syndrome. J. Neurol. Neurosurg. Psychiatry, 88: 346-352.

17. Willison HJ, Jacobs BC and van Doorn PA (2016): Guillain- Barré syndrome. Lancet, 388: 717-727.

18. Wu X, Li C, Zhang B, Shen D, Li T and Liu K (2015): Predictors for mechanical ventilation and short-term prognosis in patients with Guillain-Barre syndrome. Crit Care, 19:310346.

19.Zhang Y, Zhao $Y$ and Wang $Y$ (2018): Prognostic factors of Guillain-Barré syndrome: a 111-case retrospective review. Chinese Neurosurgical Journal, 4:14-52. 


\section{منبئات الاستجابة للعلاج بفصل البلازما في الاعتلال المناعي للأعصاب الطر فية الخرزية}

ياسر السيا مختار، طارق إبراهيم منيسي، حسان قوشتي جاد، محمد أحمد زكي قسم الأمراض العصبية، كلية الطب، جامعة الأزهر

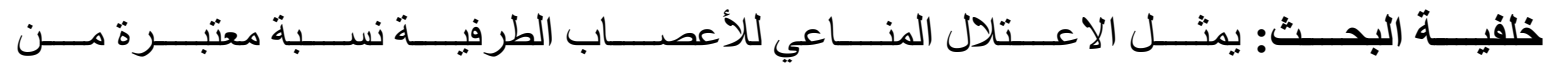

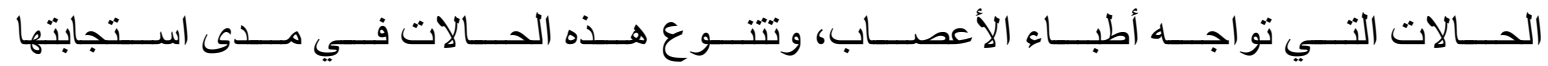
اللعلاج بجلسلت فصل البلازما، كما تتنوع المنبئات لمدى هذه الاستجابة.

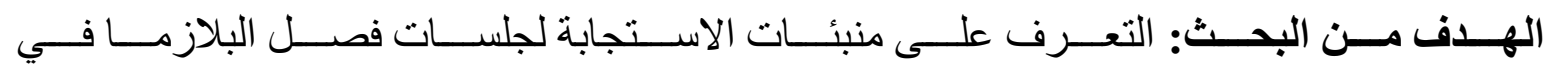
الاعنلال المناعي للأعصاب الطرفية.

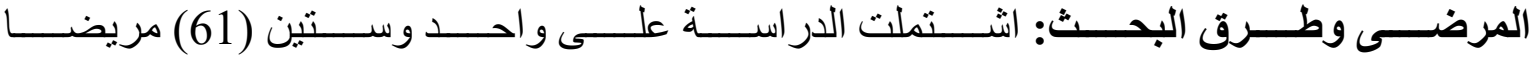

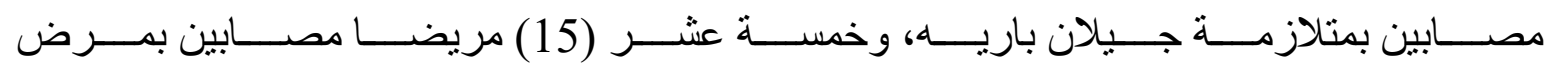

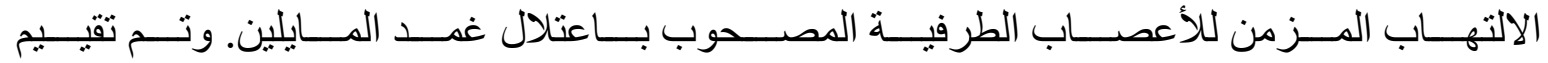

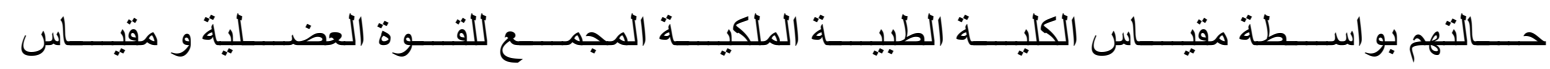

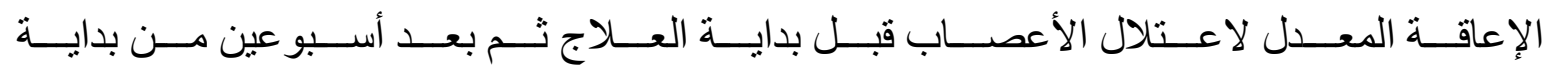

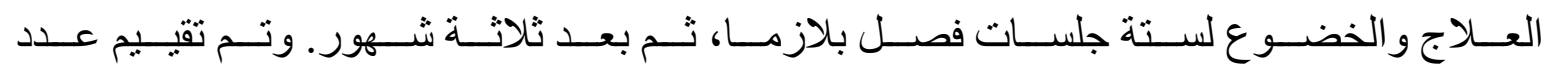

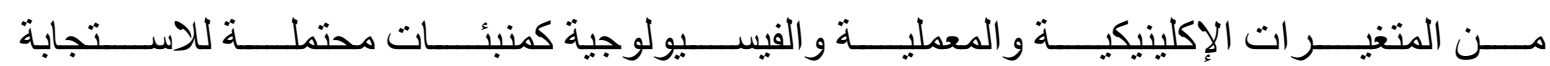
للعلاج.

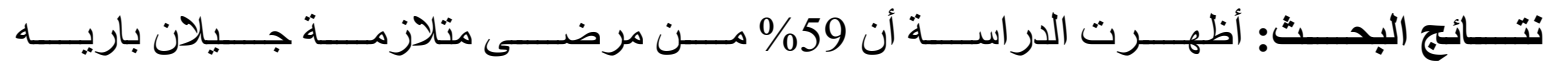

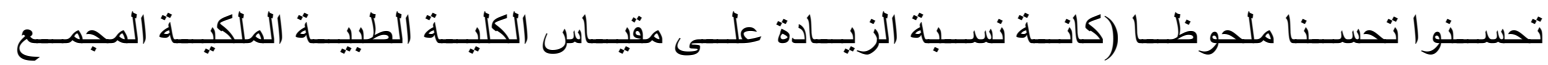

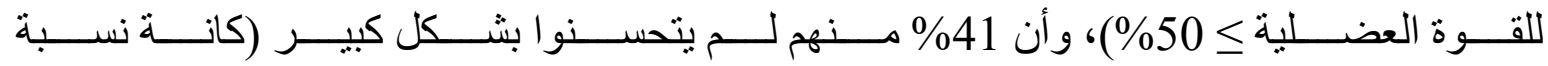

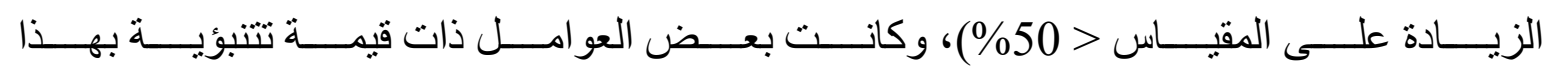

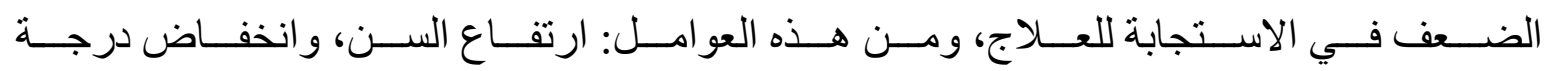

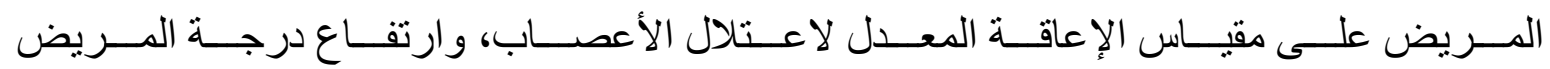

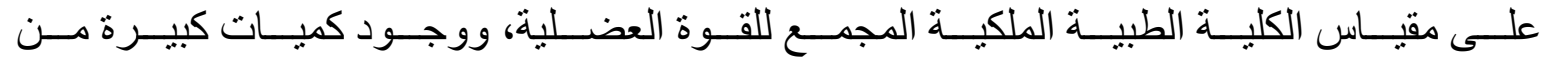

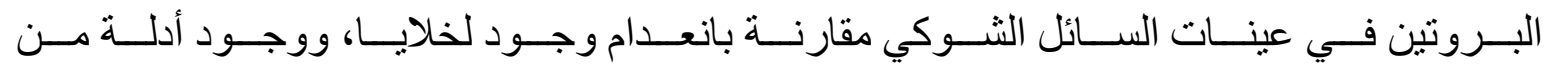

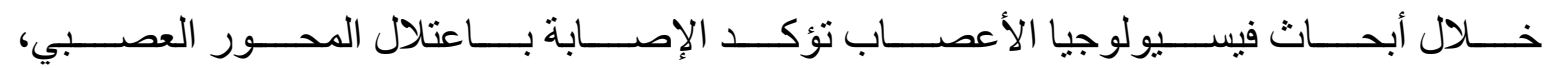




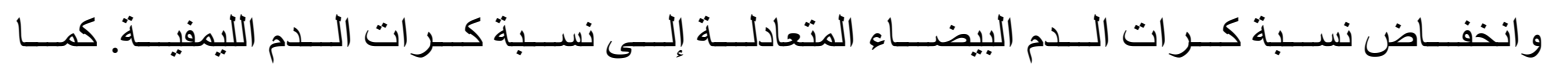

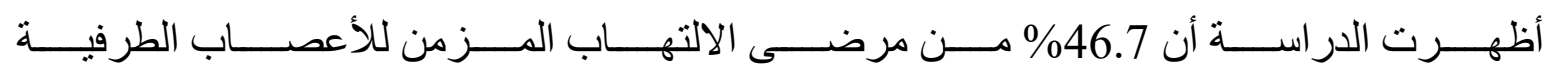

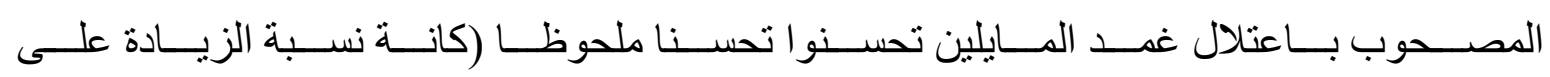

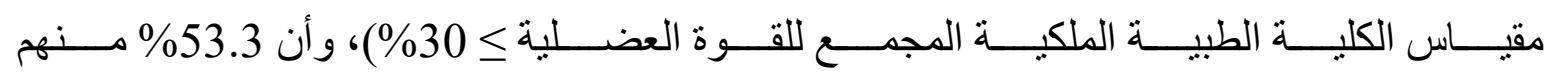

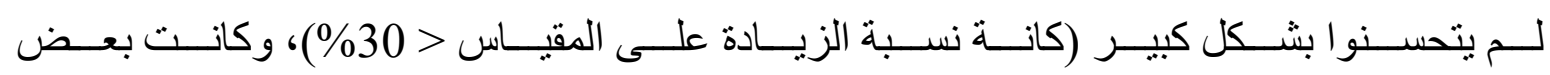

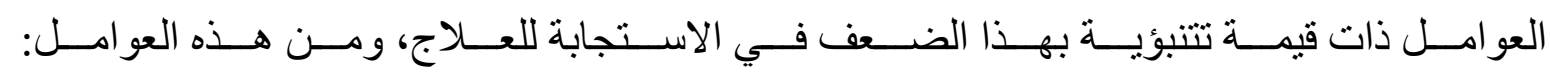

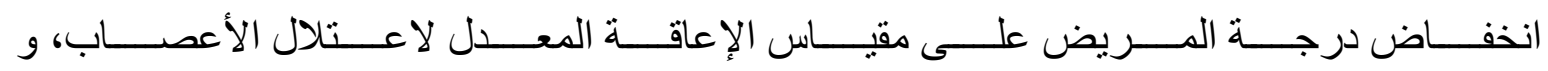

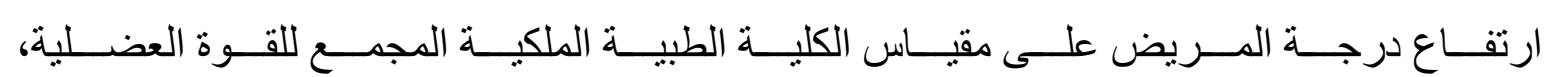

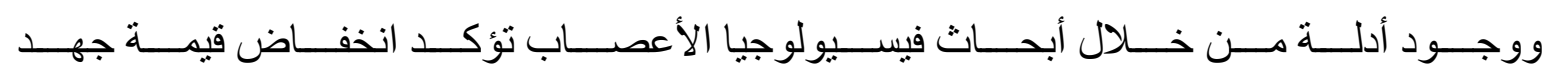

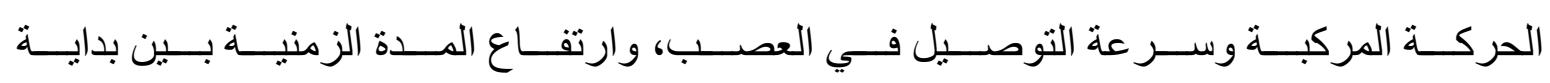
ظهور أعر اض المرض وبين تلقي العلاج.

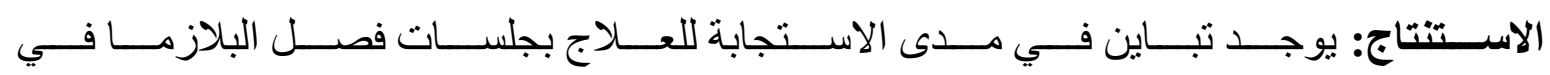

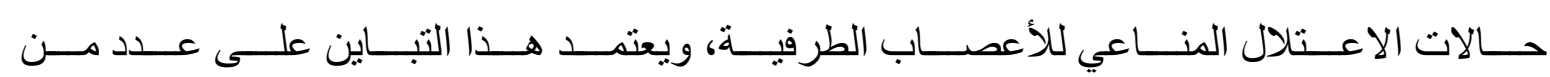
العو امل التتي يمكنها التنبوء به. 